\title{
Asistencia sanitaria femenina a finales del Antiguo Régimen: el caso del Hospital de la Caridad y Refugio de Granada ${ }^{1}$
}

\author{
Inmaculada AriAs dE SAAVEDRA AlíAS \\ Universidad de Granada \\ aarias@ugr.es \\ Miguel Luis LóPez-Guadalupe MuÑoz \\ Universidad de Granada \\ mllopez@ugr.es
}

Fecha de recepción: 20/03/2015

Fecha de aceptación: 28/04/2015

\begin{abstract}
RESUMEN
Para cubrir las necesidades asistenciales de su población, la ciudad de Granada se dotó tras la conquista de una importante red hospitalaria, que se mantuvo en líneas generales durante toda la Edad Moderna, pese a los intentos de reducir hospitales de Felipe II, o la creación del Hospicio General en 1753. Situándola en este contexto hospitalario, este artículo analiza la asistencia sanitaria dispensada en el hospital femenino a cargo de la Hermandad de la Caridad y Refugio. Con fondos procedentes de su rico archivo se lleva a cabo un estudio cuantitativo de la asistencia prestada durante la segunda mitad del siglo XVIII, analizando aspectos tan interesantes como ingresos de enfermas, procedencia geográfica y social, edad, estado civil, número de hijos, mortalidad en el hospital, así como de las principales enfermedades que dieron lugar a las hospitalizaciones. Sus resultados matizan algunas afirmaciones tópicas acerca de la mala calidad de la asistencia sanitaria durante el Antiguo Régimen.
\end{abstract}

Palabras clave: Asistencia sanitaria, hospitales, historia de las mujeres, siglo XVIII.

\section{Female Sanitary Assistance in the End of the Ancient Régime: The Hospital of Caridad $y$ Refugio in Granada}

\begin{abstract}
The city of Granada equipped itself with an important hospital network in order to take care of its population's assistance needs. Said network was maintained throughout the entire Modern Ages in spite Felipe II's attempts at reducing the number of hospitals and the creation of the Hospicio General in 1753. This article analyzes the sanitary assistance provided in a women's hospital under the Brotherhood of Caridad $y$ Refugio. A quantitative study of the assistance provided during the second half of the eighteenth century is performed using documents from its ample archive, and including aspects as in-
\end{abstract}

1 Investigación realizada en el marco del proyecto: "El hecho cotidiano en la Monarquía Española de la Edad Moderna: lo doméstico, entre lo privado y lo público. Historia comparada entre el interior y la periferia. 3. Granada" (HAR2011-26435-C03-03), financiado por el Ministerio de Economía y Competitividad. 
teresting as the admission of the sick, their geographical and social origins, ages, marital status, number of children, the mortality rate in the hospital, and the main illnesses that caused hospitalizations. This work's results nuance several topical affirmations about the overall lack of quality of sanitary assistance in the Ancien Régime.

Key words: Sanitary Assistance, Hospitals, Women's History, Eighteenth Century.

\section{LOS HOSPITALES DE GRANADA DURANTE EL ANTIGUO RÉGIMEN}

Desde los años inmediatos a la conquista de la ciudad, en el Reino de Granada se fue articulando una importante red hospitalaria para cubrir las necesidades asistenciales de su población. La Iglesia Metropolitana granadina, de patronato regio ${ }^{2}$, tuvo un fuerte protagonismo en la fundación de hospitales, la mayoría de los cuales pueden ser considerados de carácter diocesano, otros centros están ligados a órdenes religiosas, hermandades o patronatos, que canalizaron a través de ellos el ejercicio de la ca$\operatorname{ridad}^{3}$. Por lo que se refiere a la diócesis de Granada, aunque se crearon fundaciones de carácter hospitalario en ciudades como Alhama, Almuñécar, Loja, Motril, Ugíjar, y otros lugares, en general fueron de escasa magnitud e importancia y con el tiempo se vieron reducidos a meros hospitales de tránsito ${ }^{4}$.

Fue lógicamente la ciudad de Granada la que concentró los hospitales más impor$\operatorname{tantes}^{5}$. Mientras que en las comarcas fuera de la capital el dominio de los hospitales eclesiásticos era absoluto, en la ciudad se observaba una mayor variedad. El centro de mayor envergadura era el Hospital Real ${ }^{6}$, fundado por los Reyes Católicos, que acogía en su origen a contagiados de bubas y a locos. Junto a él se hallaban dos centros especializados: el hospital de San Lázaro, para enfermos de lepra, y el hospital de Ntra. Sra. del Pilar, para tiñosos. También había en la ciudad fundaciones propias de cofradías con el fin de atender preferentemente a sus asociados ${ }^{7}, \operatorname{como}_{\text {ocurría con el }}$ hospital de San Sebastián (que pronto quedaría sin actividad), el del Corpus Christi y el de Ntra. Sra. de las Angustias, así como pequeños hospitales de fundación particu-

2 SUBERBIOLA MARTíNEZ, J.: Real Patronato de Granada. El arzobispo Talavera, la Iglesia y el Estado Moderno (1486-1516), Granada, Caja General de Ahorros y Monte de Piedad, 1985.

3 Sobre este tema véase: CALLAHAN, W. J.: "Caridad, sociedad y economía en el siglo XVIII", Moneda y crédito, 146 (1978), pp.65-77 y SOUBERYROUX, J.: "El encuentro del pobre y la sociedad: asistencia y represión en el Madrid del siglo XVIII", Estudios de Historia Social, 20-21 (1982), p. 9 y MARCOS MARTÍN, A.: "La Iglesia y la beneficencia en la Corona de Castilla durante la época moderna. Mitos y realidades", en ABREU, L. (ed.): Igreja, caridade e assitência na península Ibérica (sécs. XVI-XVIII), Évora, Ed. Colibri/ CIDEHUS, 2004, p. 131.

4 LÓPEZ-GUADALUPE MUÑOZ, M. L.: "Hospitales rurales en la diócesis de Granada (siglo XVIII)", en PÉREZ ÁlVAREZ, Ma. J. y MARTÍN GARCÍA, A. (eds.): Campos y campesinos en la España Moderna, León, Fundación Española de Historia Moderna, 2012, p. 1.475.

5 Una visión de conjunto en CAMBIL FERNÁNDEZ, Ma. E.: Los hospitales de Granada (siglos XVIXXI): tipología, catálogo e historia, Granada, Universidad, 2010.

6 FÉLEZ LUBELZA, C.: El Hospital Real de Granada, Granada, Universidad, 1979 y VALENZUELA CANDELARIO, J.: "El insigne y suntuoso Hospital Real de Granada (I). Las fundaciones reales y la reunión hospitalaria (1501-1526)", Dynamis, 23 (2003), pp. 193-219.

7 LÓPEZ-GUADALUPE MUÑOZ, M. L.: La labor benéfico-social de las cofradías en la Granada Moderna, Granada, Universidad, 1994. 
lar que, por lo general se convirtieron en centros subsidiarios, para "convalecencia" de otros mayores (hospitales de Navas y de Santa Cruz), o como albergue de transeúntes (Hospital de Peregrinos). Otros eran propios de grupos sociales concretos, como el hospital de la Resurrección destinado exclusivamente a los moriscos, que se extinguió con la desaparición de este colectivo en la ciudad, o el hospital sostenido por el arte mayor de la seda y destinado exclusivamente a sus agremiados. Estos hospitales en su mayoría eran centros de reducidas dimensiones. Aunque algunos de ellos no eran propiamente eclesiásticos, en todos era muy grande el protagonismo del clero, especialmente a través de cargos como el de rector, que solía ser eclesiástico, y, desde luego, del de capellán, ambos indican la presencia rotunda de la Iglesia en este campo ${ }^{8}$. Y máxime tras la celebración del concilio de Trento y la institución de una orden hospitalaria, nacida precisamente en Granada; desde la segunda mitad del Quinientos se intensificó esa labor hospitalaria asentada en la virtud de la caridad.

De todos modos, el grueso de los centros hospitalarios granadinos eran propiamente eclesiásticos, por su origen y funcionalidad, aunque también en muchos de estos casos se proyecta la alargada sombra de la Corona que ostentaba el regio patronato sobre la diócesis. Se trataba de centros propios del Arzobispado, como el hospital de la Encarnación o de Santa Ana, para varones, o de alguna orden religiosa, como el de San Juan de Dios, que contaba con tres salas para hombres (para tratar fiebres ardientes, llagas y heridas, incurables) y una sala para mujeres.

Esta compleja realidad hospitalaria no se vio afectada por la política de reducción de centros llevada a cabo por Felipe II $^{9}$, que tuvo consecuencias decisivas en localidades como Sevilla, Madrid, Valladolid o Salamanca ${ }^{10}$. La profusión de centros continuó en la siguiente centuria. Según la relación de la visita ad limina del arzobispo Ríos y Guzmán, en 1685 la ciudad de Granada contaba con catorce hospitales ${ }^{11}$.

Más decisiva fue la acción reformista de los ministros ilustrados, para intentar mejorar un sistema insuficiente en tiempos "normales" y que mostraba sus carencias especialmente en períodos epidémicos, una reforma que debe entenderse no sólo desde el prisma de la racionalización sanitario-benéfica, sino también desde la óptica del regalismo. A ese impulso reformista obedece la transformación en 1753 del Hospital Real de Granada en Hospicio General ${ }^{12}$, uno de los primeros en todo el reino. A la finalidad original de asistir a unciados, locos y pobres, se añadieron entonces nuevas

8 Las interacciones en el campo de la caridad entre el Estado y la Iglesia fueron mutuas (vid. HUGUET TEMES, T.: "Iglesia, socorro de pobres y asistencia hospitalaria en el Madrid de los Austrias (1561-1700): algunas reflexiones", en ABREU, op. cit. (nota 3), p. 66.

9 VALENZUELA CANDELARIO, J.: "Economía moral de la asistencia médica. La reducción hospitalaria en la Granada del siglo XVI", Chronica Nova, 33 (2007), pp. 333-368.

10 MAZA ZORRILLA, E.: Pobreza y asistencia social en España. Siglos XVI al XX, Valladolid, Universidad, 1987 , pp. 163 y ss.

11 LÓPEZ-GUADALUPE MUÑOZ, M. L.: "La diócesis de Granada en la visita ad limina de 1685", Chronica Nova, 20 (1992), pp. 379-380.

12 Vid. SANZ SAMPELAYO, J.: "Hospital Real y Hospicio Real en la Granada del siglo XVIII", Anuario de Historia Moderna y Contemporánea, 1 (1974), pp. 69-88 y MORENO RODRÍGUEZ, R. M., "Las ordenanzas y constituciones del Real Hospicio de Granada de 1756: la tentativa asistencial ilustrada ante la cultura caritativa”, en VALENZUELA CANDELARIO, J., MORENO RODRÍGUEZ, R. M. y GIRÓN IRUESTE, F.: El Hospital Real de Granada y sus constituciones de gobierno (1593-1857). Asistencia a los pobres y regulación social, Granada, Universidad, 2008, pp. 103-199. 
obligaciones, muy acordes con la mentalidad paternalista de la época: “...la recogida y atención de los pobres de la ciudad..., la reeducación de mujeres públicas, el acoger a los niños expósitos, la reunificación de las propiedades y rentas de los centros que antes se dedicaban con independencia a estas obras sociales, la realización de convenios con aquellos otros que pudieran ayudar o fuera necesaria su colaboración, el tratamiento de unciones a los sifilíticos y la continuación de la asistencia a los dementes" ${ }^{13}$. El mantenimiento del Hospicio exigía la concentración de servicios y de rentas. En el primer caso, los logros fueron escasos. Junto a los servicios tradicionales del Hospital Real, el nuevo hospicio asumió algunas funciones no propiamente hospitalarias: la Casa Cuna para expósitos, la Casa de Recogidas de Sta. María Egipciaca, el colegio de Niños de la Providencia para emplearlos en fábricas, el colegio de huérfanas de la Purísima Concepción y, más tarde, la Casa del Amparo, para atender partos secretos. Fracasó en cambio alguna concentración hospitalaria, como la del centro destinado a los tiñosos. La reunión de rentas, muy dispersas y dispares fue más efectiva ${ }^{14}$, afectando a numerosos centros, tanto de la capital (como el Hospital de Sta. Ana -con una fuerte oposición eclesiástica-, el de Navas y el colegio de los Niños de la Doctrina), como del resto de la diócesis (hospitales de Loja y Alhama y los de tránsito de Santa Fe, Albolote, Pinos Puente e Íllora) ${ }^{15}$, pero también resultó insuficiente. El hospital de la Caridad y Refugio no resultó afectado, en parte por la fama de su nobiliaria hermandad y especialmente por atender a la población femenina, lo que constituía una útil singularidad.

Algunas cifras nos pueden acercar mejor a la realidad hospitalaria granadina tras estas acciones racionalizadoras. En 1770 el Hospital Real, ya Hospicio General, atendió a 666 aquejados del "mal francés", 324 pobres y locos, 379 niños expósitos y 30 niñas huérfanas ${ }^{16}$. Y aunque las cifras son estimativas, el Hospital de San Juan de Dios, con un número muy elevado de camas -hasta 200-, en el último tercio del Setecientos, contabilizaba la atención de más de 2.000 enfermos, que registraban largas estancias en el mismo, debido a la condición de incurables de algunos de ellos. Por su parte el hospital de Santa Ana, con 50 camas, atendía una media de 900 enfermos varones anuales, con estancias que tenían una duración media de 18 días. El número de camas de este hospital eclesiástico aumentó considerablemente al trasladarse en 1777 a las casas de los condes de Luque y Villamena, en el Campo del Príncipe ${ }^{17}$.

13 SANZ SAMPELAYO, J.: Granada en el siglo XVIII, Granada, Diputación Provincial, 1980, p. 202 y MORENO RODRÍGUEZ, R. M.: "La larga historia del confinamiento para remediar la pobreza. El Hospicio General de Pobres de Granada, 1753-1768", Chronica Nova, 30 (2003-2004), pp. 511-555.

14 Desde juros y diezmos hasta legados y limosnas, pasando por patronatos, detracciones de rentas reales y "despojos" del matadero. Vid. LÓPEZ-GUADALUPE MUÑOZ, M. L.: "Orden, gobierno y piedad. Hospitales en la diócesis de Granada en la segunda mitad del siglo XVIII", Revista del Centro de Estudios Históricos de Granada y su Reino, $2^{a}$ época, 10-11 (1996-97), pp. 318-319. Para la creación del Hospicio se ordenaba tomar 200.000 reales de la "cuarta decimal destinada para los pontificales" (LÓPEZ, M. Á.: Los arzobispos de Granada. Retratos y semblanzas, Granada, Arzobispado, 1993, p. 207).

15 SANZ SAMPELAYO, op. cit. (nota 13), pp. 203-204. Hubo también pequeños hospitales, generalmente de tránsito, en Órgiva, Montefrío, Iznalloz, Colomera, Moclín o Guadahortuna, pero estos no se agregaron al Hospicio (Archivo de la Parroquia del Sagrario, leg. 28).

16 Ibídem, pp. 218 y ss.

17 Ibídem, p. 195. Las transformaciones de este inmueble en ACALE SÁNCHEZ, F.: El Hospital Militar de Granada. De palacio renacentista a Escuela de Arquitectura, Sevilla, Caja San Fernando, 2003. 
En este contexto desempeñó su labor asistencial el Hospital de la Caridad y Refugio, objeto de este estudio. Fruto de la labor asistencial de una hermandad caritativa, que inició su labor en los albores de la Granada cristiana, se trataba de un hospital exclusivamente para mujeres; cumplía, por tanto, una función similar, a nivel diocesano, a la del hospital de Santa Ana, que acogía a varones. Aunque, como toda la asistencia hospitalaria en el Antiguo Régimen, estaba dirigido a las clases populares, muy proclives siempre a caer en el ámbito de la pobreza, se trataba de un hospital que, como el de Santa Ana o el de las Angustias, se situaba entre los centros que, además de ofrecer una separación de sexos considerada entonces muy conveniente -como se verá, aproximadamente $2 / 3$ de las atendidas eran solteras o viudas, y en cuanto a la edad más del $70 \%$ contaban entre 11 y 50 años-, dispensaba una asistencia de mayor calidad y acogía a sectores populares menos marginales que los acogidos en los centros más nutridos (hospitales Real y de San Juan de Dios). En alguna ocasión hemos calificado a este hospital como un centro "de élite" ${ }^{18}$. De esta valoración se hace eco el arzobispo de la ciudad, el ilustrado D. Antonio Jorge y Galbán -opuesto en 1777 a la reunión de los hospitales granadinos, entre otros motivos, "por la mayor dificultad de conserbar quietud y buen orden en casa mui grande y avitada de individuos de ambos sexos"-, quien destacaba que: “...para lograr cama en los de las Angustias, donde son siete, o en el de Santa Ana, donde son de treinta y cinco a cincuenta, se hazían especiales empeños, porque el menor número y mayor cuidado haze preferir estas casas en la común estimación a la de San Juan de Dios y a otra cualquiera general de común concurrencia, yendo a aquéllas sin la natural renuencia que suele haver en personas que se han criado con regalo, lo que no sucede en los hospitales generales, pues muchas vezes acontece que algunos prefieren el morir en sus rincones antes que ir o permitir que los lleben a recobrar la salud a ellos" 19 .

A la labor del hospital del Refugio se dirigen las reflexiones que siguen, con el propósito de presentar la tarea asistencial de la hermandad que lo sustenta y el funcionamiento del hospital, y analizar más detenidamente el perfil de las mujeres que a él acudían, las patologías que presentaban y el alcance de su curación en la segunda mitad del Setecientos.

\section{LA VARIADA LABOR ASISTENCIAL DE LA HERMANDAD DE LA CARIDAD Y REFUGIO DE GRANADA}

La fundación de la Hermandad del Refugio pudo acaecer algunos años antes de 1513, en el que se promulgaron sus primeras reglas. Estas reglas, renovadas varias veces a lo largo de los siglos, atendían a la máxima de ejercitar la caridad en todas sus facetas, con fidelidad al mensaje evangélico:

\footnotetext{
18 Una primera aproximación al mismo en nuestro trabajo: “¿Hospitales de élite? El hospital femenino de la Caridad y Refugio de Granada”, en PÉREZ ÁLVAREZ, M. ' J. y LOBO DE ARAUJO, M. ${ }^{a}$ M. (coords.): La respuesta social a la pobreza en la Península Ibérica durante la Edad Moderna, León, Universidad de León, 2014, pp. 55-88.

19 Archivo Histórico Nacional (AHN), Consejos, leg. 15.850, pza. 2. Informe de 18 de marzo de 1777.
} 
...el principio, fundacion de la dicha Hermandad, se originó de la devocion de algunos Fieles Clerigos, y Cavalleros, y Ciudadanos, que movidos por la gracia de Nuestro Señor, se animaron á dar de sus haziendas, y de lo que juntavan de limosnas que pedian por la Ciudad lo que era necesario para socorrer todo genero de necesidades de pobres vivos, y difuntos, exercitando todas las obras de caridad, y misericordia, vistiendo desnudos, curando enfermos, sacando presos de la carcel, rescatando cautivos, casando huerfanas, y enterrando muertos, asi ajusticiados, como ahogados en los rios, y de otras muertes desastradas, ó naturales, tan desamparados que no tuviesen caudales, ó deudos que los socorriesen para ello... ${ }^{20}$.

Aunque no era obligatoria la pertenencia a la nobleza para militar en ella, Henríquez de Jorquera la califica como "hermandad de toda la nobleza desta ciudad de Granada" 21 . Es evidente que su forma de practicar la caridad atrajo a la "alta sociedad" granadina, que encontró en sus actividades una ocasión más de afianzar su poder e influencia social. Desde su nacimiento mostró un claro carácter elitista, en sus mismas reglas se consigna como preferente la apuesta por el linaje a la hora de la admisión de hermanos: "ni baste que sea cavallero ni rico, ni abogado de la Chancillería ni con oficio grave en la República (si bien es justo que todo se mire y se tenga consideración a estas partes, que si no son las principales para el instituto de la hermandad, ayudan a lo menos a que con mejores respectos y cuydado acudan a sus obligaciones)". Este elitismo se acentuó al establecer en ochenta el número máximo de hermanos.

En poco tiempo la hermandad consiguió afianzarse y adquirió una justa fama, la que valoró en 1525 la Confraternidad de Sacerdotes de San Pedro ad vincula -asociación entre cuyos fines se encontraba el socorro de los presos pobres- para transferirle ciertos censos perpetuos y otras rentas, con la certeza de que los caballeros de la Caridad garantizarían mejor ese servicio. En sus primeros años tenía su sede en el Convento de Santa Cruz la Real, de la Orden de Predicadores, donde los hermanos disfrutaron de una capilla de enterramiento. Más tarde, cuando asumieron entre sus fines la curación de enfermas, se trasladaron a un nuevo edificio, en la colación de San Gil, frente al Hospital del Corpus Christi.

La estructura organizativa, establecida en sus primitivas reglas, fue evolucionando a través de sucesivas reformas estatutarias ${ }^{22}$, las más importantes se produjeron en 1639, al asociarse con la Hermandad del Refugio de Madrid, constituida en $1618^{23}$. El gobierno de la hermandad estaba encomendado al hermano mayor, cargo anual elegido el día de los Inocentes (28 de diciembre), auxiliado por otros oficios: mayordomo,

20 Un estudio sobre la hermandad y su labor asistencial en LÓPEZ-GUADALUPE MUÑOZ, M. L. y LÓPEZ MOYA, R.: La Hermandad de la Caridad y Refugio de Granada: 500 años de hospitalidad, Granada, Ayuntamiento, 2013. La síntesis que ofrecemos bebe lógicamente en esta obra.

21 Anales de Granada, ed. de A. Marín Ocete, estudio preliminar e índices de P. Gan Giménez y L. Moreno Garzón, Granada, Universidad/Ayuntamiento, 1987, vol. I, p. 258.

22 Las primeras reformas tuvieron lugar en 1534-36 y continuaron en 1582, 1631 y 1639. Las reglas, con nuevas modificaciones, se reimprimieron en 1676, 1716 y 1759. En 1798 se procedió a aprobar nuevas constituciones, visadas por el Consejo de Castilla y últimas del período de nuestro estudio, que se publicaron en 1801 .

23 CALlaHAM, W. J.: La Santa y Real Hermandad del Refugio y Piedad de Madrid, 1618-1832, Madrid, CSIC, 1980. 
consiliarios, comisarios de fiestas, visitadores de enfermos, etc. Especial significación tenía el rector del hospital, un eclesiástico de plena confianza de la hermandad, que a partir de 1690 estuvo auxiliado por un vicerrector. A ellos hay que añadir el personal asalariado, como enfermera, médico, cirujano o barbero, además del escribano o secretario, "persona de talento, versada en papeles, laboriosa y desocupada".

A lo largo de su trayectoria la hermandad granadina fue asumiendo la práctica de diversas obras de misericordia que dieron lugar a un elenco muy variado de prácticas asistenciales. Su agregación al Refugio de Madrid, hermandad más moderna que no llegó a tener un hospital, pero que desplegaba diversas actuaciones caritativas, tuvo mucho que ver con esta variedad de acciones. La corporación granadina, que contó con unas saneadas y variadas rentas para el ejercicio de la caridad ${ }^{24}$, intentó asignar recursos específicos, procedentes de donaciones, patronatos de legos y legados varios, a cada actividad asistencial.

El esfuerzo mayor se dirigió al mantenimiento del hospital de mujeres, pero, como se ha indicado, no fue la única obra de caridad que ejercieron. La limosna a los pobres fue una de las prácticas más frecuentadas. A mediados del Seiscientos implantó la costumbre de socorrer a pobres mendigos en la víspera del Domingo de Ramos, en un acto multitudinario del mejor gusto barroco, en el que, con el concurso de los Jesuitas, se asistía a mendigos forasteros reclutados en mesones y posadas, en una acción que buscaba aunar los auxilios espiritual y material, en un significativo tiempo litúrgico. Tras administrar la confesión y la comunión a los pobres, en la iglesia de la Compañía, eran conducidos en procesión hasta las dependencias del hospital, donde se daba a cada uno un real y dos libras de pan, previa entrega de la cédula de confesión y comunión recibida. El número de pobres atraído por esta actuación llegó a alcanzar en algunos años varios millares, comprometiendo el fondo general de limosnas de la hermandad -logrado mediante demandas semanales en las calles granadinas y los Jueves y Viernes Santos en los templos- , y provocando dudas sobre la condición de los socorridos y escrúpulos de conciencia acerca de si era lícito atraer a los sacramentos con el señuelo de una recompensa material.

Otra actividad asumida desde fecha muy temprana fue la de asistir a los presos de la cárcel de la ciudad. La acción era doble: atender las necesidades de los encarcelados, demandando para ello limosnas callejeras, y gestionar el pago de la deuda para quienes estaban presos por este motivo. Además de dedicar a este fin los fondos de la hermandad de sacerdotes ya citada, los hermanos pagaban una cuota mensual y realizaban demandas callejeras semanales, algo que, sin duda, debía causar un gran efecto social y moral, al exponer en la calle a estos nobles pidiendo limosna. En cuanto a la ayuda alimenticia, según las reglas de 1716 se realizaba así:

...los viernes de cada semana se a de dar de comer pan y pescado, o en lugar de pescado habas, a los pobres presos de la cárcel de esta Ciudad, como se suele hazer y ha hecho siempre... Y alguna vez asistirá el Hermano Mayor, u otro Hermano a quien

\footnotetext{
${ }^{24}$ Según el Catastro de Ensenada era la hermandad granadina con mayores rentas fijas (por arriendo de tierras, alquiler de casas y réditos de censos), que ascendían al año a casi 40.000 reales. En la desamortización de Godoy se le enajenaron bienes raíces por valor de casi medio millón de reales (LÓPEZ-GUADALUPE MUÑOZ, op. cit. (nota 7), p. 82).
} 
lo cometiere, a repartirles la comida, porque no se la coman los sirvientes de la cárcel y los pobres se queden sin comer.

Al mismo tiempo que la atención a los encarcelados se instituyó la dotación de doncellas. También en este caso se imprime un aire de honorabilidad y moralidad, pues se exigía a las jóvenes que

...fuesen pobres, honestas y virtuosas, nacidas de legítimo matrimonio, libres, y que no huviesen sido ni fuesen siervas, ni moças de soldada, y que tuviesen más de diez y seis años, e hijas de vezinos de Granada y de sus arrabales, y que lo ayan sido de más de cinco años, y que vivan en casa de sus padres o parientes dentro del quarto grado, o en Monasterio, o en otra casa honesta.

Cada doncella recibía para el casamiento cinco mil maravedíes, al menos desde 1536. En 1582 se subió el montante de la dote hasta veinte ducados. Aquellas mozas pertenecían a familias pobres, pero honradas. Un ejemplo más de que esta hermandad dirigió su labor asistencial a pobres vergonzantes, a familias desclasadas que debían ser socorridas con dignidad, sin que se viera afectado su honor. Por ello se puso cuidado en preservar la identidad de las agraciadas. Sólo los dos Diputados para la llamada Suerte de las Doncellas se informaban de que las solicitantes cumplían los requisitos establecidos. El sorteo de las elegidas se realizaba en enero, el segundo domingo después de Epifanía, y para mayor discreción no constaba el nombre de las jóvenes, sino el de los hermanos que las apadrinaban. Las agraciadas debían contraer matrimonio en el plazo de un año, o perderían la dote en caso contrario.

Aunque sólo con carácter temporal, también ejerció la hermandad la labor de enseñanza a doncellas. Entre 1612 y 1639 estuvo asociado a la corporación el colegio de la Concepción para niñas huérfanas, trasladado después a la calle de la Cárcel y más tarde a la de Recogidas, junto al beaterio que albergaba a mujeres procedentes del mundo de la prostitución o recluidas allí por motivos no menos miserables. Se trataba, según Henríquez de Jorquera de "doncellas colejiales que con la renta salen para casadas o profesan monjas y an de ser algunas de los linajes de los fundadores, a que se han agregado otras obras pías; su primera fundación fue en el hospital de la Caridad"25. Respondía, pues, a la necesidad de protección (dotación de doncellas, instrucción de huérfanas, asistencia sanitaria, entierro digno) que en todos los órdenes precisaba la mujer, conforme al concepto de honra imperante en la sociedad del Antiguo Régimen ${ }^{26}$. También se destinaron a ellas otras actuaciones de la hermandad,

25 Anales de Granada, op. cit. (nota 21) vol. I, p. 250.

26 En este sentido, los modernos enfoques de género han subrayado el papel de las mujeres en las redes de parentela que actúan como formas primarias de previsión (CARBONELL, M.: "Género, pobreza y estrategias de supervivencia. Barcelona, siglo XVIII", Boletín de la Asociación de Demografía Histórica, XII, 2/3 (1994), pp. 3011-316). Sin duda las formas tradicionales de caridad que amalgamaban irónicamente en los hospitales el orgullo (ć́vico) y la humildad (cristiana), de modo que "las mujeres aprendieron a utilizar el paternalismo de un orden social que las consideraba más necesitadas de protección" (PERRY, M. E.: Ni espada rota ni mujer que trota, Barcelona, Crítica, 1993, p. 173). La caridad cristiana actuaba entonces tratando de preservar el honor depositado en la "virtud" sexual de la mujer (BOLUFER, M.: "Entre historia social e historia cultural: la historiografía sobre la pobreza y caridad en la época moderna”, Historia Social, 43 (2002), p. 122). 
como los repartos de tejidos. En 1631 se estableció el reparto por Navidad de "doze o diez y seis mantehuelos de paño", repartidos entre las mujeres necesitadas a arbitrio del hermano mayor. En este caso, como en el de las dotes, parece evidente que la hermandad disponía de una nómina de familias en dificultades a las que asistir. Se exigía que fueran "mugeres pobres honradas".

También se atendió, tal vez de forma transitoria, la redención de cautivos, en virtud de una manda expresamente realizada por el Doctor Marmolejo, indicándose en las reglas de 1716 que era la obra de caridad que aún faltaba por hacer en el hospital. Para ello se ayudaría de la labor de los Trinitarios, orden especializada en el rescate de cautivos. Pero los beneficiarios de esta labor asistencial se restringían a cautivos naturales de Andújar y Granada, o en grave peligro de apostasía.

Por último, aunque de forma restringida, la hermandad procedió al entierro de difuntos, ocupándose de las enfermas que fallecían en su hospital: "las que murieren se enterrarán en dicho hospital, en el lugar que les está señalado, o en la iglesia de él, si ella lo mandare y dexare limosna para ello".

\section{EL HOSPITAL DE MUJERES}

El mantenimiento de un hospital de mujeres fue la actividad más importante de la Hermandad de la Caridad y Refugio de Granada, y a la que dedicó mayores esfuerzos. Empezó a funcionar en 1532, se mantuvo abierto durante toda la Edad Moderna y siglos siguientes, llegando incluso hasta la actualidad, aunque transformado desde mediados del siglo XX en residencia de ancianas. Las sucesivas reglas de la corporación regularon la organización de este centro que durante el Antiguo Régimen, dada la mentalidad religiosa de la época, ofrecía asistencia no sólo sanitaria, sino también espiritual, a mujeres pobres y enfermas. Las constituciones publicadas en 1716 y las aprobadas por el Consejo el 11 de noviembre de 1800, e impresas en 1801, vigentes durante el periodo de nuestro estudio, recogen esta preocupación a lo largo de su articulado.

En su primera etapa, cuando aún tenía su sede en el convento de los dominicos, el hospital solo disponía de una docena de camas para enfermas de calenturas y tres más para incurables. Más tarde, nuevas rentas posibilitaron el traslado a la calle Elvira y una ampliación considerable del hospital que en el siglo XVIII contaba con treinta camas, veinte para ingresos de enfermas y diez más -con la dotación inicial realizada por María Jofre- para convalecientes, de un mínimo de ocho días en él. Esta dotación hacía de este centro el tercero en importancia de la ciudad, tras los hospitales de San Juan de Dios y la Encarnación ${ }^{27}$-el Hospital Real, superior en el número de alojados, tenía también el carácter de asilo- y el más específico en lo que se refiere a asistencia femenina y, probablemente, por esto y el esmero de su asistencia, el más demandado. A falta de un mayor detalle documental, las constituciones del hospital, pese a su carácter oficial, son la fuente esencial para conocer su funcionamiento.

27 LÓPEZ-GUADALUPE MUÑOZ, op. cit. (nota 14), p. 314. 
Las reglas de 1716 establecían restricciones a las mujeres para ingresar: "que no sean incurables, ni enfermas de mal francés, ni heridas" ${ }^{28}$. No obstante, en los libros de enfermas del siglo XVIII se anotan hospitalizaciones "en cama de incurables", lo que indica que esta restricción fue anulada. En el preámbulo de las constituciones de 1801, se afirma: "no solo se emplea esta hermandad en asistir a quantas permiten sus fondos, sino en cuidar algunas incurables...", limitando las restricciones de ingreso a "un número de enfermas pobres, correspondientes a sus fondos, las quales no padezcan los males habituales venéreos, rigurosamente contagiosos, ni de cirugía, si no sobrevienen de la misma enfermedad" ${ }^{29}$. La exclusión de las mujeres con enfermedades venéreas respondía a consideraciones de carácter sanitario y moral, discriminando a las dedicadas a la prostitución, que no eran bienvenidas en una institución sanitaria con un sesgo de honorabilidad muy alto en sus patronos y que pretendía tenerlo también en sus usuarias. Un hospital que dispensaba una asistencia sanitaria muy aceptable, desde nuestra óptica, dado el contexto de la época, y era preferido frente a otros de carácter más general. A pesar de su número relativamente alto de camas, el volumen de aspirantes a ser tratadas en él solía exceder la oferta. Por eso las constituciones recomendaban que la hospitalización se hiciera, "atendiendo siempre a la de mayor urgencia, según la clase de la enfermedad e indigencia de la concurrente" 30 , una decisión que tomaba el rector del hospital, por consejo del médico y bajo la supervisión del hermano mayor. Según la documentación conservada, el hospital solía estar casi siempre con todas sus camas ocupadas. Cada enferma al ingresar recibía sábanas y almohadas limpias, y se le administraba la confesión y la comunión. Permanecía ingresada de forma gratuita todo el tiempo necesario para su curación, ocupándose el hospital de su manutención y tratamiento, y de ofrecerle todos los servicios necesarios, tanto en lo tocante a la salud de su cuerpo como de su alma administración de los sacramentos a cualquier hora del día o de la noche, catequesis para mejor su formación religiosa, etc.-. Una vez recuperadas, las enfermas pasaban a la sala de convalecientes, donde permanecían hasta su total restablecimiento, "ocho días por lo menos, y más lo que al médico y hermano mayor pareciere" ${ }^{31}$. A principios del siglo XVIII seis eran las camas de convalecientes, más tarde el número se elevó a diez, una tercera parte de los puestos del hospital. Por su parte, las enfermas que morían eran enterradas en el mismo hospital, o en su iglesia -esto solo si dejaban limosnas suficientes para ello ${ }^{32}$. Para el entierro de las enfermas pobres se estableció una concordia con la vecina Parroquia de San Gil, a cuya colación pertenecía el hospital.

El hospital estaba dirigido por un sacerdote secular, que ejercía como rector. Esta dirección eclesiástica, bastante común en los hospitales de la época, evidencia la anteposición de las preocupaciones espirituales, aunque en este caso sin descuidar las

\footnotetext{
28 Constituciones de la hermandad y hospital de la Charidad y Refugio de esta ciudad de Graada..., Granada, Imprenta de la Santísima Trinidad, 1716, Título V, constitución I.

29 Constituciones de la Illustre y Venerable Hermandad de la Caridad y Hospital del Refugio de Granada: con un reglamento sobre la administración de caudales del mismo hospital, Granada, Imprenta de Moreno, 1801, Título I, constitución I.

30 Constituciones... 1801, Título VI, constitución III.

31 Constituciones... 1716, Título V, constitución III.

32 Constituciones... 1716, Título V, constitución II.
} 
estrictamente sanitarias ${ }^{33}$. Las constituciones de 1716 establecen su elección por los cofrades anualmente, aunque con posibilidad de reelecciones, que debieron ser frecuentes. Así, por ejemplo, el rector del hospital en 1787, don Nicolás de la Rosa y Esquivel, seguía siéndolo en 1804. No es de extrañar, por tanto, que en los estatutos de 1801 no se determine el tiempo del mandato, aunque se establece que "la hermandad podrá despedirle quando tenga por conveniente" y convocar una nueva elección ${ }^{34}$. En ambos casos se detallan las cualidades para desempeñar el cargo: "El rector debe ser persona muy virtuosa y docta y caritativa, para que mejor pueda usar el oficio, y que sea aprobado por el ordinario, para confessar generalmente hombres y mugeres y para administrar los santos sacramentos; y de tanta virtud que sea exemplo a todos su modestia, y caridad, y de más edad que quarenta años"35. Se exigía una persona virtuosa y madura, para evitar problemas en el trato con personas de otro sexo. Tenía obligación de residir en el mismo hospital, para dar asistencia espiritual a las enfermas en cualquier momento que lo necesitasen. Las constituciones encarecen mucho este deber, cuyo incumplimiento podía llevar incluso al cese del rector, que, siempre que se ausentara por causa justificada, debía dejar otro sacerdote que lo sustituyera.

Las obligaciones del rector eran de carácter espiritual y material. Las primeras eran las más importantes: confesar y dar la comunión a las enfermas el día de su ingreso en el hospital, administrarles estos sacramentos e incluso la extremaunción, si fuera necesaria, durante su hospitalización "a cualquier hora de la noche o del día" ${ }^{36}$, confortarlas y asistirlas en la hora de la muerte ${ }^{37}$, ocuparse del cumplimiento de las mandas espirituales de las fallecidas e incluso proporcionar a las ingresadas la bula para la salvación de su alma. Tenía también a su cargo el culto de la iglesia del hospital, así como decir una misa todos los domingos y festivos "para consuelo de las enfermas y convalecientes" ${ }^{\prime 3}$ en el altar o pequeño oratorio situado en una de las salas de la enfermería; debía celebrar también todas las misas fruto de legados hechos a favor de la hermandad ${ }^{39}$, así como impartir catequesis a las enfermas y personal subalterno del hospital. Sus obligaciones no eran solo de carácter espiritual, también supervisaba la asistencia sanitaria y el funcionamiento general del hospital. Decidía, con asesoramiento médico, el ingreso de las enfermas, así como su traslado a las salas de convalecientes y su salida de alta de la institución, dando cuenta inmediata al hermano mayor. Acompañaba al médico en las dos visitas diarias -de mañana y tarde-, que se giraban a las enfermas, vigilando con especial cuidado la administración de medicinas y remedios, y estaba también presente durante las comidas y las cenas. $\mathrm{Su}$

\footnotetext{
33 LÓPEZ-GUADALUPE MUÑOZ, op. cit. (nota 14), p. 306.

34 Constituciones... 1801, Título V, constitución XIII.

35 Constituciones... 1716, Título III, constitución II. En los estatutos renovados se habla solo de "suficiente edad e instrucción" (Constituciones... 1801, Título V, constitución I).

36 Constituciones... 1716, Título III, constitución IV.

37 Las Constituciones de 1801 se detienen en este punto. Entre las obligaciones del rector respecto a las enfermas destacan: "su confortación y asistencia en la hora de la muerte, teniendo el mayor cuidado en acordar con el médico, según el estado y tiempo de la fiebre, la buena razón de confesarlas, para que no se frustren los santos e interesantes fines con que fue expedida la Bula Pontificia que del caso trata" (Título V, constitución $\mathrm{VI})$.

38 Constituciones... 1716, Título V, constitución IV.

39 Constituciones... 1716, Título III, constitución VI.
} 
presencia junto a las enfermas era continua. Tenía también importantes obligaciones burocráticas: registraba en libros separados las entradas de enfermas en el hospital y los fallecimientos que se producían; tomaba nota de los escasos bienes que declaraban las ingresadas, así como de las mandas de las que fallecían, dando cuenta del cumplimiento de las mismas al hermano mayor. También debía llevar un libro donde se anotaran las memorias de misas y limosnas a favor del hospital y la hermandad, y de velar por su cumplimiento, así como de las libranzas hechas por los contadores para el mantenimiento del hospital. También debía llevar inventario de todo lo que había en la sacristía, iglesia y enfermería del hospital. Dada la complejidad de sus obligaciones, las constituciones de 1801 establecen la existencia de un vicerrector o capellán, sacerdote secular con las mismas condiciones personales que el rector, que desempeñe el cargo "por el tiempo que la hermandad tenga a bien" ${ }^{40}$, cuya obligación principal era administrar los sacramentos y otros auxilios espirituales a las enfermas y sustituir al rector en caso de ausencia o enfermedad.

A principios del siglo XVIII el personal sanitario estaba formado por un médico, un barbero sangrador, una enfermera y un portero, que recibían sus salarios de las rentas del hospital ${ }^{41}$. Además, si era necesario, se recurría a un cirujano, al que se le abonaban los servicios prestados. Por eso las constituciones de 1716 aconsejan que en las contrataciones de médicos deben preferirse a los que reúnan estas dos condiciones ${ }^{42}$. Los estatutos de 1801 regulan que la contratación de los médicos se convoque por edictos públicos en la puerta del hospital, dejando un tiempo para que los hermanos se informen de las cualidades de los aspirantes, que eran elegidos en Junta General $^{43}$. Los médicos estaban obligados a prestar asistencia no sólo a las enfermas del hospital, sino también al personal del mismo, que recibía atención sanitaria en el mismo centro, si era necesario ${ }^{44}$. Además de intervenir de manera decisiva en los ingresos de enfermas en el hospital, competencia del rector y hermano mayor, decidían sobre el tratamiento, convalecencia y alta de las enfermas. Pasaban visita en el hospital dos veces al día, mañana y tarde, y estaban obligados a prescribir por escrito las medicinas y remedios, así como a controlar la alimentación de las ingresadas. Parece que a principios del siglo XIX la figura del cirujano había dejado de ser circunstancial, contratándose a uno de estos facultativos, en sustitución del barbero sangrador de anteriores etapas; pasaba visita en sala diariamente junto con el médico, realizando las operaciones prescritas por este último.

También establecía el hospital un concierto con un boticario "de cuya botica se den las medicinas necesarias para las enfermas y convalecientes", que presentaba cuentas semanales de los remedios proporcionados, anotadas en un libro por el rector y pagadas anualmente por el mayordomo ${ }^{45}$. Dada la condición benéfica del hospital, sus

\footnotetext{
40 Constituciones... 1801, Título V, constitución XIV.

41 Constituciones... 1716, Título IV, constitución XIII.

42 Constituciones... 1716, Título IV, constitución XIV.

43 Constituciones... 1801, Título VI, constitución I.

44 El 13 de mayo de 1787 "Petronila de Vargas Machuca, enfermera, entró enferma en su cuarto" (Libro donde se asientan las enfermas que entran a curarse en este Hospital de la Charidad y Refugio de Granada que da principio en enero de 1781..., núm. 207; en Archivo de la Hermandad de la Caridad y Refugio de Granada, en adelante AHCRG).

45 Constituciones... 1716, Título IV, constitución XV.
} 
constituciones instan a procurar de dicho establecimiento la correspondiente rebaja, "entretanto no se establezca en la casa la botica suficiente para su consumo" ${ }^{46}$. No tenemos noticia de que el Hospital de la Caridad llegara a tener su propia botica, al menos durante el Antiguo Régimen.

Además del personal sanitario, el hospital contaba con personal subalterno y de servicio, contratados por la Junta General de la Hermandad, a propuesta del hermano mayor. En 1716 eran solo una enfermera y un portero; a principios del siglo XIX el personal de servicio se había multiplicado, los estatutos de 1801 les dedican el título VII: "De la familia y el portero". "Los sirvientes del hospital -dice su constitución primera- deberán ser por ahora ocho, a saber: la enfermera mayor o ama de llaves, la enfermera y las dos ayudantes; una de estas con destino a velar las enfermas; la cocinera y la ayudante de cocina; la costurera y una lavandera" ${ }^{47}$. Todas ellas "de muy buenas costumbres y de suficiente edad, sin enlace que las distraiga". Contratadas por el hermano mayor, residían en las casas del hospital del que "ninguna saldrá sin muy urgente causa". Como puede observarse, este hospital, como otros de la época, imponía a su personal el modelo de vida monástica ${ }^{48}$. La enfermera mayor o ama de llaves, se ocupaba de la custodia y suministro de ropas, alimentos y medicinas. La otra enfermera y una de las ayudantes se ocupaban de asistir a las enfermas durante el día, mientras que la ayudante llamada veladora realizaba el turno nocturno, desde las diez de la noche hasta las seis de la mañana ${ }^{49}$. En cuanto al portero, tenía variadas ocupaciones: el cuidado y aseo de la iglesia del hospital, realizar los encargos que la hermandad, hermano mayor y rector le hicieran, convocar a los hermanos a las juntas de la hermandad, controlando las asistencias y estando presente durante las mismas, traer diariamente los víveres y medicinas para el consumo diario del hospital y controlar el acceso al mismo de las personas ajenas a la institución, cerrando las puertas del edificio cada noche, a las nueve en invierno y a las diez en verano, hasta la nueva apertura a la mañana siguiente ${ }^{50}$. Las constituciones hacen hincapié en que el hospital no debe ser turbado en su sosiego y tranquilidad por personas ajenas a la propia institución, especialmente en horario nocturno. Las reglas impresas en 1716 prohíben de forma expresa que "ninguna persona (fuera de los dichos rector, y ministros y enfermas) puedan habitar ni dormir noche ninguna en el dicho hospital" ${ }^{51}$. Esta prohibición supuso el cambio de ubicación del colegio de doncellas huérfanas que hasta entonces había compartido casa con el hospital, en unos locales arrendados en sus casas, lo que suponía unas rentas adicionales al mismo.

La supervisión del hospital se encomendaba al hermano mayor y a dos hermanos nombrados por turnos semanales, que tenían que visitar a las enfermas diariamente a la hora de las comidas. Las constituciones describen minuciosamente cómo deben

\footnotetext{
46 Constituciones... 1801, Título VI, constitución VIII.

47 Constituciones... 1801, Título VII, constitución I.

48 SA, I. dos Gimarâes: "Habitar: del espacio a los objetos", en GARCÍA FERNÁNDEZ, M. (dir.): Cultura material y vida cotidiana moderna: escenarios, Madrid, Sílex, 2013, p. 118.

49 Constituciones... 1801, Título VII, constitución III.

50 Constituciones... 1801, Título VII, constituciones IV-VII.

51 Constituciones... 1716, Título IV, constitución XVI.
} 
comprobar que las enfermas reciben el mejor tratamiento médico ${ }^{52}$ y la alimentación adecuada $^{53}$. Otros dos hermanos, también por turnos semanales, se encargaban de pedir limosna por las calles y domicilios de Granada, para contribuir a sufragar los gastos del hospital, aunque éste se mantenía sobre todo con los abundantes bienes y rentas procedentes de donaciones, acumulados a lo largo de su vida: tierras, censos, obras pías y patronatos de legos sobre todo ${ }^{54}$.

\section{REALIDAD SOCIAL HOSPITALARIA}

Para conocer la realidad del Hospital de la Caridad y Refugio de Granada, más allá del análisis de sus constituciones, hemos procedido a la explotación y estudio de algunas de sus ricas fuentes primarias, en concreto los datos correspondientes a ingresos y fallecimientos de enfermas en el hospital entre 1746 y $1804^{55}$, lo que nos ha permitido reconstruir las series completas para todo el periodo, excepto el año 1759, en que no hemos podido calcular las cifras de hospitalizaciones. Además de estos datos de carácter más general, hemos procedido a la explotación exhaustiva de una muestra de dos años completos, 1787 y 1804. Los resultados obtenidos en ambos muestran una gran similitud.

Entre 1746 y $1804-48$ años, descontado 1759-, fueron asistidas en el hospital granadino un total de 35.665 enfermas pobres, una cifra muy importante, que arroja una media de 743 mujeres hospitalizadas cada año. De esta alta cifra de ingresadas, solo fallecieron en el hospital 2.908 enfermas, lo que supone un porcentaje bastante bajo, inferior al 10 por ciento de los ingresos, concretamente del 8,15 por ciento del total, lo que desmiente el lugar común que suele repetirse de que en el Antiguo Régimen se iba a los hospitales a morir. Al menos en el Hospital de la Caridad y Refugio de Granada la mayoría de las mujeres que pasaron por él salieron curadas y restablecidas. Podemos considerar, por tanto, que la asistencia sanitaria en esta institución fue

\footnotetext{
52 "Los hermanos que por semanas asistieren a su comida, procurando verlo y preguntando a las mismas enfermas; y si les falta algo, o en la cura y servicio ay negligencia; y si el médico las visita a horas convenientes y si las sangrías se hazen a tiempo, para que si hubiere falta se remedie" (Constituciones... 1716, Título V, constitución III).

53 “examinarán si las enfermas están bien asistidas, si se les da de comer y cenar lo que piden y deben tomar (según sus accidentes), si los guisos están bien sazonados, y si los abastos son los mejores, como que se trata con inapetentes, y que el objeto de los fundadores siempre aspiraría a lo mexor, para que se logre la más perfecta curación de las pobres que se acojen al hospital buscando consuelo y alivio". En Propuesta de nuevas Constituciones para presentar al Consejo de Castilla, s.a., Título 17, constitución $3^{\mathrm{a}}$., Archivo de la Hermandad de la Caridad y Refugio de Granada (AHCRG).

54 El Catastro de Ensenada le regula 27.790 reales de ingresos anuales (LÓPEZ MUÑOZ, M. L.: "Las cofradías y hermandades de la ciudad de Granada en el Catastro de Ensenada", Revista del Centro de Estudios Históricos de Granada y su Reino, 2. ${ }^{a}$ Época, 5 (1991), p. 234).

55 Libro donde se asientan las enfermas que entran a curarse en este Hospital de la Charidad y Refugio de Granada que da principio en enero de 1781 ...; Libro donde se apuntan las enfermas que entran a su curación en este Hospital de la Caridad y Refugio de esta ciudad de Granada para el año 1799...; Libro donde se sientan las hermanas enfermas que mueren en el Hospital de la Caridad y Refugio de esta ciudad de Granada, que da principio en enero del año de 1787... Todos ellos en AHCRG.
} 
más que aceptable y, a juzgar por los resultados, puede calificarse de buena, a falta de poder establecer comparaciones con otros centros.

Esta buena asistencia hospitalaria se basaba en primer lugar en la posibilidad de que las enfermas pasaran en cama el tiempo necesario para el restablecimiento. Hemos calculado la estancia media de las enfermas en el hospital, los dos años de la muestra arrojan una cifra parecida, un poco más alta en 1787 en que las enfermas estuvieron algo más de 12 días ingresadas, mientras que en 1804, en que se produjo un número mayor de ingresos, la estancia no llega a los 11 días (10,73 días por enferma, para ser más exactos). A estas estancias, habría que sumar en ambos casos los períodos de convalecencia, que no hemos podido determinar con exactitud porque no se conserva la documentación relativa a ésta, pero sabemos, por las disposiciones que establece el hospital que estos periodos de convalecencia supondrían, como mínimo, ocho días. En consecuencia, la estancia de las enfermas en el hospital de la Caridad y Refugio de Granada podría acercarse bastante a los 20 días, una cifra importante para el siglo XVIII, que explica los buenos resultados sanitarios de la institución. De todos modos, estamos hablando de valores medios. Refiriéndonos solo a las cifras de hospitalización, sin contar la convalecencia, hallamos una casuística muy variada, desde personas que permanecen más de 60 días en el hospital, a otras que fallecen a las pocas horas de ingresar en él.

\begin{tabular}{|c|c|c|c|}
\hline Años & Ingresos & Defunciones & \% \\
\hline $1746-1750$ & 2.728 & 314 & 11.51 \\
\hline $1751-1755$ & 2.950 & 291 & 9.86 \\
\hline $1756-1760^{*}$ & 2.471 & 200 & 8.09 \\
\hline $1761-1765$ & 3.453 & 229 & 6.63 \\
\hline $1766-1770$ & 3.030 & 159 & 5.25 \\
\hline $1771-1775$ & 2.801 & 177 & 6.32 \\
\hline $1776-1780$ & 2.767 & 188 & 6.79 \\
\hline $1781-1785$ & 3.397 & 260 & 7.65 \\
\hline $1786-1790$ & 3.053 & 285 & 9.34 \\
\hline $1791-1795$ & 3.023 & 258 & 8.53 \\
\hline $1796-1800$ & 3.245 & 280 & 8.63 \\
\hline $1801-1804^{* *}$ & 2.747 & 267 & 9.72 \\
\hline TOTALES & 35.665 & 2.908 & 8.15 \\
\hline
\end{tabular}

*Solo 4 años, sin datos de 1759; ** Solo 4 años.

Tabla. 1. Ingresos y defunciones del Hospital de la Caridad y Refugio de Granada (1740-1804). Fuente: AHCRG, Libros de ingresos de enfermas y Libros de fallecidas.

Examinadas las cifras de hospitalizaciones y muertes de este periodo distribuidas por quinquenios (cuadro 1), observamos que el número de fallecidas es siempre inferior al 10 por ciento de las hospitalizadas. Sólo en el periodo entre 1746-1750 las muertes superaron este porcentaje, por el contrario, las cifras más bajas de defunciones las encontramos en las décadas de los 60 y 70, donde los fallecimientos están por debajo del 7 por ciento del total de hospitalizaciones. De todos modos, las diferencias a lo largo del periodo no son muy grandes. 


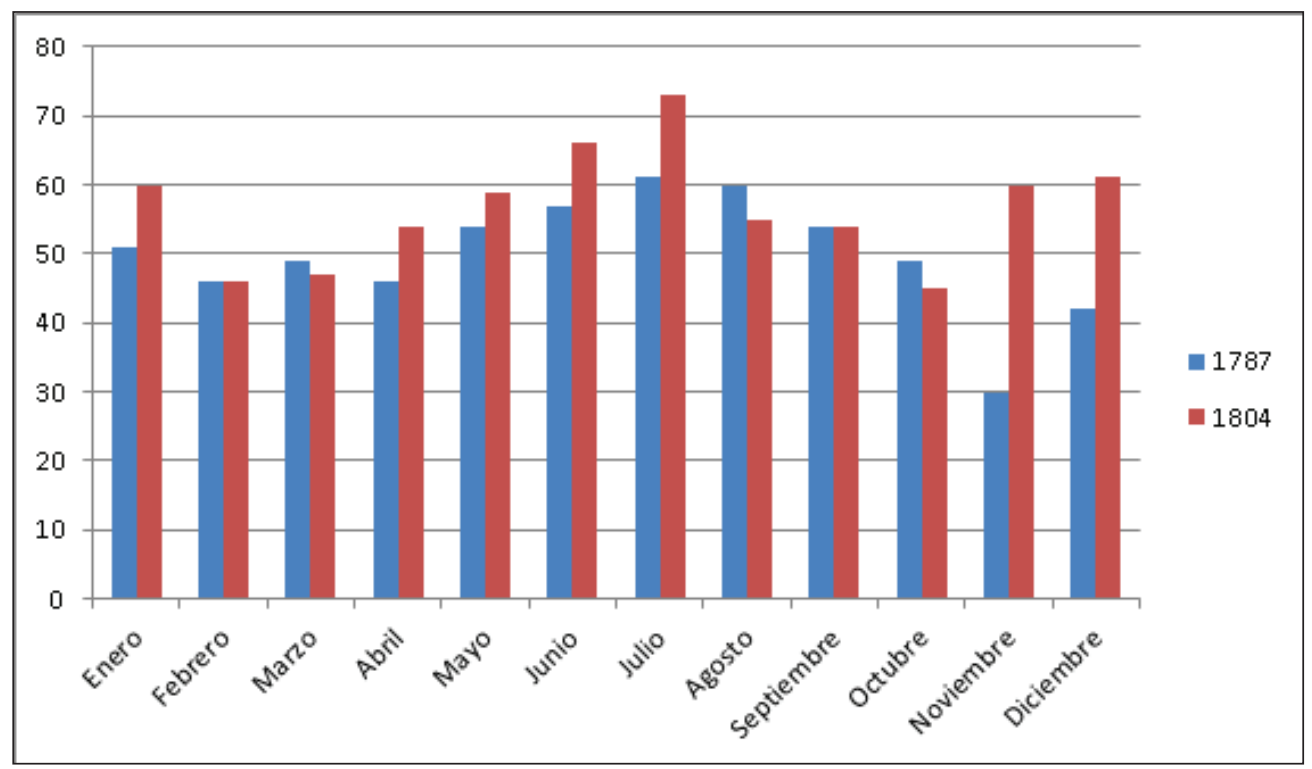

Tabla 2. Ingresos en el Hospital de la Caridad y Refugio de Granada (1787 y 1804).

Fuente: AHCRG, Libros de ingresos de enfermas.

Los ingresos de enfermas se distribuyen de manera bastante uniforme a lo largo de los meses en los dos años que hemos estudiado. No hay diferencias significativas entre unos meses y otros, lo que nos impide hablar de estacionalidad en los ingresos en el hospital. Eso es debido, pensamos, al hecho de que la posibilidad de acceder al hospital estaba siempre condicionada por la disponibilidad de camas vacantes; aunque en las enfermedades más comunes hubiera una cierta estacionalidad, esta no se refleja en el ritmo por el que las enfermas acceden al hospital, porque este estaba siempre sujeto a la disponibilidad de plazas. Sí se observa una mayor estacionalidad en la distribución de las muertes a lo largo del año, en ambos años puede detectarse una mayor mortalidad en los meses de invierno, como suele ser habitual. En 1804 se observa así mismo un número de defunciones relativamente alto a partir de los meses de verano, y con especial significación en el otoño. En este caso concreto eran los primeros estragos de la epidemia de fiebre amarilla que desde Cádiz asoló Andalucía y cuyo contagio se dejó sentir en Granada a partir del verano de este año ${ }^{56}$.

Los registros de hospitalización de las enfermas, así como los de fallecimiento, proporcionan bastante información sobre las mismas. Las constituciones de 1801 prescriben la obligación de que ambos asientos se hagan "cuidando nunca falte en estas partidas la expresión del estado, naturaleza, vecindad y demás artículos de filiación" ${ }^{57}$, pero en realidad estos datos se venían recogiendo ya desde mediados del

56 PESET, M. y J. L.: Muerte en España: política y sociedad entre la peste y el cólera, Madrid, Seminarios y Ediciones, 1972, p. 108.

57 Constituciones... 1801, Título II, artículo VI. 
siglo XVIII. De su explotación podemos extraer abundante información que nos ayuda a ajustar el perfil de las mujeres que acudían al hospital de la Caridad y Refugio.

\begin{tabular}{|c|c|c|c|c|c|c|c|c|}
\hline Año & Solteras & $\mathbf{\%}$ & Casadas & \% & Viudas & \% & s.d. & \% \\
\hline 1787 & 211 & 35,17 & 209 & 34,83 & 174 & 29,00 & 6 & 1 \\
\hline 1804 & 240 & 35,29 & 208 & 30,58 & 221 & 32,50 & 11 & 1,61 \\
\hline
\end{tabular}

Tabla 3. Estado civil de las enfermas. Hospital de la Caridad y Refugio de Granada. Fuente: AHCRG, Libros de ingresos de enfermas.

En cuanto al estado civil de las mujeres que acceden al hospital, en ambos años la distribución es bastante homogénea entre casadas, solteras y viudas. En los dos años hay un ligero predominio de las solteras sobre el resto. En cualquier caso, las mujeres que acudían a curarse o a morir al hospital eran sobre todo mujeres solas -solteras o viudas- más de las dos terceras partes, la presencia de las casadas es mucho menor.

\begin{tabular}{|l|l|l|l|l|l|l|l|l|l|l|l|}
\hline Año & $\begin{array}{l}\text { Con } \\
\text { hijos }\end{array}$ & $\begin{array}{l}\text { Sin } \\
\text { hijos }\end{array}$ & $\mathbf{1}$ hijo & $\mathbf{2}$ hijos & $\mathbf{3}$ hijos & $\mathbf{4}$ hijos & $\mathbf{5}$ hijos & $\mathbf{6}$ hijos & $\mathbf{7}$ hijos & 8 hijos & $\begin{array}{l}\mathbf{9} \\
\text { hijos }\end{array}$ \\
\hline 1787 & 266 & 334 & 92 & 72 & 46 & 27 & 21 & 6 & 2 & & \\
\hline 1804 & 303 & 366 & 91 & 84 & 59 & 31 & 23 & 7 & 5 & 2 & 1 \\
\hline
\end{tabular}

Tabla 4. Número de hijos por enferma. Hospital de la Caridad y Refugio de Granada. Fuente: AHCRG, Libros de ingresos de enfermas.

En ambos años entre las hospitalizadas predominan también las mujeres que no tienen hijos (en torno al $55 \%$ en los dos años): junto a mujeres solteras, casadas y viudas sin hijos van en mayor medida al hospital que las casadas o viudas con hijos. Da la impresión que las mujeres que tenían hijos acudían menos al hospital y en mayor medida pasaban las enfermedades en su casa, atendidas por su familia.

También proporcionan los registros de entradas en el hospital información sobre el número de hijos que tenían las mujeres que eran madres, ya fueran casadas o viudas -al menos en los años de muestra no hemos encontrado hospitalizada ninguna mujer soltera que tuviera hijos-. También en este caso hallamos una gran coincidencia en los datos de los dos años estudiados. La mayoría de las mujeres tienen un solo hijo. En ambos años las madres de un hijo único superan el treinta por ciento de las mujeres con hijos hospitalizadas -el 34,59 en 1787, el 30,03 en 1804-. Algo más bajo es el porcentaje de las que tienen dos hijos -el 27,07 y el 27,72 respectivamente-. Desciende algo más aún el número de mujeres que son madres de tres hijos: el 17,29 y el 19,47 respectivamente. Las que tienen cuatro hijos apenas superan el diez por ciento en ambos años. Por último, las que tienen más de cuatro hijos presentan unos valores mucho menores. Los datos de las mujeres que iban al hospital estaban bastante en consonancia con los valores demográficos generales de la sociedad granadina en aquel momento, donde el número de hijos vivos por familia no era muy alto. 


\begin{tabular}{|l|c|c|c|c|}
\hline & \multicolumn{2}{|c|}{$\mathbf{1 7 8 7}$} & \multicolumn{2}{|c|}{$\mathbf{1 8 0 4}$} \\
\hline Edad & $\mathrm{N}^{\mathbf{0}}$ & $\%$ & $\mathrm{~N}^{\mathbf{0}}$ & $\%$ \\
\hline $1-10$ años & 3 & 0,5 & 21 & 3,08 \\
\hline $11-20$ años & 109 & 18,16 & 117 & 17,20 \\
\hline 21-30 años & 107 & 17,83 & 118 & 17,35 \\
\hline 31-40 años & 88 & 14,66 & 140 & 20,58 \\
\hline $41-50$ años & 100 & 16,66 & 113 & 16,61 \\
\hline 51-60 años & 71 & 11,83 & 81 & 11,91 \\
\hline Más de 60 & 64 & 10,66 & 74 & 10,88 \\
\hline No consta & 58 & 9,66 & 16 & 2,35 \\
\hline Totales & 600 & & 680 & \\
\hline
\end{tabular}

Tabla 5. Edad de las enfermas. Hospital de la Caridad y Refugio de Granada. Fuente: AHCRG, Libros de ingresos de enfermas.

En cuanto a la edad de las enfermas, es un dato que también se suele consignar en los registros, aunque no siempre. En las hospitalizaciones producidas en los primeros meses de 1787 falta este dato en muchas de las enfermas, lo que supone la ausencia en casi el 10 por ciento de los registros de este año. En 1804 la falta de este dato es mucho menos significativa.

También en este caso hay una gran coherencia en los datos de los dos años de la muestra. Apenas aparecen hospitalizadas niñas menores de diez años, aunque los valores son algo más altos en 1804. En el resto de los grupos de edad, las hospitalizaciones son bastante homogéneas, descendiendo significativamente entre las mayores de 60 años, debido a que pocas mujeres alcanzaban estas edades, muy elevadas para una época en que la esperanza de vida era bastante baja ${ }^{58}$.

\begin{tabular}{|c|c|c|c|c|c|c|}
\hline Año & Granada & \% & Fuera de G. & \% & Sin datos & \% \\
\hline 1787 & 511 & 85,16 & 82 & 13,66 & 7 & 1,16 \\
\hline 1804 & 582 & 85,58 & 87 & 12,79 & 11 & 1,61 \\
\hline
\end{tabular}

Tabla 6. Lugar de residencia de las enfermas. Hospital Caridad y Refugio de Granada.

Fuente: AHCRG, Libros de ingresos de enfermas.

En los registros se consigna la parroquia de la que son feligresas las enfermas, lo que nos permite conocer su lugar de residencia, una información que poseemos en casi todos los casos y en la que también encontramos una gran homogeneidad. El hospital de la Caridad y Refugio acogió sobre todo a mujeres residentes en Granada, en los dos años estudiados más del 85 por ciento de las enfermas residen en la capital. El factor de proximidad contó de forma determinante en las hospitalizaciones. Las

\footnotetext{
58 La esperanza media de vida para hombres y mujeres españoles se situaba en el siglo XVIII en 26,8 años (PÉREZ MOREDA, V.: Las crisis de mortalidad de la España interior. Siglos XVI-XIX, Madrid, Siglo XXI, 1980, p. 141). Era algo más baja que la europea, que se situaba para el periodo de 1750-1769 en torno a los 34 años de media (LIVI BACCI, M.: Historia mínima de la población mundial, Barcelona, 1990, p. 115).
} 
que no vivían en la capital, lo hacían en pueblos cercanos, la mayoría de ellos de la zona de la Vega de Granada: Santa Fe, Churriana, Atarfe, Belicena, Peligros, Maracena, Armilla, Alfacar, etc.

En 1787 solo 82 de las enfermas ingresadas en el hospital vivían fuera de la ciudad de Granada. La mayoría proceden de las comarcas más cercanas a Granada, la Vega y la Sierra ${ }^{59}$. Solo dos procedían de lugares más distantes: una de Alhama, en la comarca del Temple, y otra de Huelma, en el obispado de Jaén. También se hospitalizó este año a una transeúnte, sin domicilio conocido.

No muy diferente es la realidad de 1804. De las 87 enfermas ingresadas en el hospital residentes fuera de Granada, 82 pertenecían a pueblos de la diócesis granadina y la mayoría procedían de la zona más cercana a la capital. De las comarcas de la Vega y de la Sierra se hospitalizaron 68 mujeres $^{60}$. De la comarca de los Montes y Poniente se ingresaron ocho enfermas: tres de Moclín, y el resto de Huétor Tájar, Íllora, Iznalloz, Montefrio y Píñar. Sólo cinco procedían del Valle de Lecrín y de la Costa: dos de Almuñécar, y el resto de Lobres, Mondújar y Padul. Tan sólo una enferma era de la Alpujarra, concretamente de Mecina Bombarón. En cuanto a las procedentes de otras diócesis, solo fueron cinco entre las ingresadas en 1804 y procedían de lugares como Alcudia de Guadix, Córdoba, La Carolina, Martos y Loranca (diócesis de Sigüenza).

\begin{tabular}{|l|c|c|c|c|}
\hline & \multicolumn{2}{|c|}{$\mathbf{1 7 8 7}$} & \multicolumn{2}{|c|}{$\mathbf{1 8 0 4}$} \\
\hline Parroquia & $\mathrm{N}^{\mathbf{0}}$ & $\%$ & $\mathrm{~N}^{\mathbf{0}}$ & $\%$ \\
\hline Sta. Ana & 42 & 8,21 & 21 & 3,60 \\
\hline S. Andrés & 6 & 1,17 & 43 & 7,38 \\
\hline Angustias & 45 & 8,80 & 45 & 7,73 \\
\hline S. Bartolomé & 8 & 1,56 & 8 & 1,37 \\
\hline S. Cecilio & 28 & 5,47 & 39 & 6,70 \\
\hline S. Cristóbal & 18 & 3,52 & 13 & 2,23 \\
\hline Encarnación & 23 & 4,50 & 27 & 4,63 \\
\hline Sta. Escolástica & 27 & 5,28 & 36 & 6,18 \\
\hline S. Gregorio & 3 & 0,58 & 6 & 1,03 \\
\hline S. Gil & 11 & 2,15 & 24 & 4,12 \\
\hline S. Ildefonso & 112 & 21,91 & 57 & 9,79 \\
\hline S. José & 13 & 2,54 & 23 & 3.95 \\
\hline S. Juan Reyes & 17 & 3,32 & 9 & 1,54 \\
\hline S. Justo y Pastor & 14 & 2,73 & 19 & 3,26 \\
\hline
\end{tabular}

59 Santa Fe destaca sobre todos los demás con 17 enfermas ingresadas, seguida a mucha distancia de Churriana (7 enfermas), Atarfe (6 enfermas); Belicena, Maracena y Peligros (con 5 enfermas cada una), Alfacar y Armilla (4 enfermas por pueblo), Ogíjares (3 enfermas), El Soto de Roma, Dílar, Guevéjar y Monachil (2 enfermas de cada pueblo), del resto de los pueblos que aparecen este año, solo se consigna una enferma en el hospital: Alhendín, Ambroz, Cájar, Cúllar, Chauchina, Chimeneas, El Fargue, Dúrcal, Jérez del Marquesado, Jun, Otura, Pinos Genil, Pinos Puente, Pulianas, Quéntar y Ventas de Huelma.

60 También en este caso Santa Fe destaca con 19 ingresadas, seguida de Pinos Genil con 12, Churriana con 5 ingresadas, Calicasas, Guéjar Sierra y Peligros (tres enfermas cada uno), Maracena, Pinos Puente y Quéntar (con 2 enfermas cada uno). Ingresaron una enferma poblaciones como Albolote, Alfacar, Alhendín, Atarfe, Belicena, Cájar, Caparacena, Chauchina, Cúllar, Dílar, El Fargue, Gójar, Huétor Santillán, La Zubia, Lobres, Mondújar, Nívar, Otura, Padul y Pulianas. 


\begin{tabular}{|l|c|c|c|c|}
\hline S. Luis & 7 & 1,36 & 11 & 1,89 \\
\hline Magdalena & 22 & 4,30 & 22 & 3,78 \\
\hline S. Matías & 11 & 2,15 & 22 & 3,78 \\
\hline S. Miguel & 7 & 1,36 & 11 & 1,89 \\
\hline S. Nicolás & 3 & 0,58 & 14 & 2,40 \\
\hline S. Pedro & 6 & 1,17 & 13 & 2,23 \\
\hline Sagrario & 37 & 7,24 & 45 & 7,73 \\
\hline Salvador & 25 & 4,89 & 48 & 8,24 \\
\hline Santiago & 26 & 5,08 & 26 & 4,46 \\
\hline Totales & 511 & & 582 & \\
\hline
\end{tabular}

Tabla 7. Parroquias de las enfermas residentes en Granada. H. de la Caridad y Refugio. Fuente: AHCRG, Libros de ingresos de enfermas.

En cuanto a la parroquia de residencia de las que vivían en Granada capital, los datos de los dos años de la muestra arrojan algunas diferencias. En ambos casos coincide la parroquia que más enfermas enviaba al hospital, San Ildefonso, que en 1787 contabiliza a más del 20 por ciento de las enfermas ingresadas, mientras que en 1804, aun siendo la parroquia dominante, no llegaba al 10 por ciento de las hospitalizadas. No es extraño que en esta parroquia, extramuros de la ciudad, se reclutaran muchas de las hospitalizadas; durante el siglo XVIII era de las más populosas de Granada y su población, de clases trabajadoras y con abundantes inmigrantes procedentes del campo, experimentó una notable expansión en esta centuria ${ }^{61}$, es lógico que entre sus feligresas hubiera abundancia de mujeres necesitadas, susceptibles de ser "clientes" del hospital. En 1787 a esta parroquia le seguían, en orden de importancia en el reclutamiento de enfermas, las parroquias de las Angustias, Santa Ana, el Sagrario, San Cecilio, etc., mientras que en cambio, los mayores valores en 1804 los arrojaban, después de San Ildefonso, las del Salvador, Las Angustias y el Sagrario, San Andrés, etc. De todos modos, no son diferencias sustanciales. En cualquier caso, son las parroquias más populosas las que envían en mayor proporción mujeres al hospital.

\begin{tabular}{|c|c|c|c|c|c|c|}
\hline AÑO & Granada & \% & Fuera de G. & \% & No consta & \% \\
\hline 1787 & 312 & 52,00 & 283 & 47,16 & 5 & 0,83 \\
\hline 1804 & 372 & 54,70 & 290 & 42,64 & 18 & 2,64 \\
\hline
\end{tabular}

Tabla 8. Lugar de bautismo de las enfermas. H. de la Caridad y Refugio de Granada.

Fuente: AHCRG, Libros de ingresos de enfermas.

Entre los datos que recogen los libros de enfermas, se consigna el lugar de bautismo de las mismas, lo que nos sirve para conocer dónde habían nacido. La realidad es muy parecida en los dos años de nuestro estudio. Algo más de la mitad eran naturales de la misma ciudad de Granada. Del resto, la mayoría había nacido en localidades del propio Reino de Granada, e incluso de la actual provincia de Granada. En 1787 sólo

61 SANZ SAMPELAYO, op. cit. (nota 13), p. 301. 
encontramos 29 procedentes del resto de Andalucía, que suponen algo más del 10 por ciento del total, además de dos aragonesas, tres "del reino de Valencia", una catalana, una extremeña, una de Castilla León y una nacida en el extranjero "de Génova, Italia", dice su registro de entrada en el hospital. En cuanto a 1804, aunque la proporción de las nacidas fuera de la ciudad de Granada es algo menor entre las atendidas en el hospital, aumenta la proporción de las que proceden del resto de Andalucía, que supera ligeramente el 20 por ciento de las foráneas, y sólo se hospitalizaron diez mujeres procedentes del resto de España: dos de la actual provincia de Madrid, dos de Toledo, dos de Cuenca, una extremeña, otra de Valladolid, otra de Murcia y otra de Ceuta, además de dos italianas, de la ciudad de Luca concretamente.

\begin{tabular}{|l|c|c|c|c|}
\hline & \multicolumn{2}{|c|}{$\mathbf{1 7 8 7}$} & \multicolumn{2}{|c|}{$\mathbf{1 8 0 4}$} \\
\hline Provincia Granada & 245 & $86,57 \%$ & 217 & $74,82 \%$ \\
\hline Andalucía & 29 & $10,24 \%$ & 61 & $21,03 \%$ \\
\hline Resto España & 8 & $2,82 \%$ & 10 & $3,44 \%$ \\
\hline Extranjero & 1 & $0,35 \%$ & 2 & $0,68 \%$ \\
\hline Total & 283 & & 290 & \\
\hline
\end{tabular}

Tabla 9. Lugar de bautismo de las enfermas nacidas fuera de la ciudad de Granada. Fuente: AHCRG, Libros de ingresos de enfermas.

Estos datos coinciden plenamente con la información que tenemos sobre la inmigración en la ciudad de Granada durante el siglo XVIII ${ }^{62}$ y corroboran la escasa movilidad de la población en el Antiguo Régimen y cómo se reduce a distancias cortas, especialmente al éxodo rural.

En los registros de ingreso en el hospital y en los de fallecimiento del año 1804 se consignan también, en un número importante de casos, otros datos que, aunque no se exigían en las constituciones, son de un gran interés para los historiadores actuales. Uno de ellos es la profesión del marido, en el caso de las enfermas casadas o viudas. Este dato nos permite saber la procedencia socio-profesional de sus familias. Conocemos la profesión de los esposos de 423 enfermas, algo más del 60 por ciento del total de las ingresadas este año.

\begin{tabular}{|l|c|c|}
\hline Sectores & $\mathbf{N}^{\mathbf{0}}$ & $\mathbf{\%}$ \\
\hline Primario & 178 & 42,08 \\
\hline Secundario & 144 & 34,04 \\
\hline Terciario & 80 & 18,91 \\
\hline Sin determinar & 21 & 4,96 \\
\hline
\end{tabular}

Tabla 10. Profesión de los esposos de las hospitalizadas en 1804. Fuente: AHCRG, Libros de ingresos de enfermas.

${ }^{62}$ SANZ SAMPELAYO, op. cit. (nota 13), p. 426. 
La mayoría de las mujeres ingresadas en el Hospital de la Caridad y Refugio de Granada estaban casadas con hombres dedicados a profesiones que se pueden ubicar en el sector primario, dedicadas a las actividades de la agricultura y la ganadería, lo que demuestra algo que es bien sabido, cómo incluso en un importante núcleo urbano, como era la Granada de entonces, el campo tenía una mayor presencia en sus actividades económicas. Dentro de este sector primario, la agricultura tenía un mayor peso que la ganadería, en más del 90 por ciento de estos casos la profesión que se consigna es sobre todo "del campo", o con cierta frecuencia "jornalero" y en mucha menor medida "hortelano" y "labrador". Menor significación tenía entre los maridos de las enfermas la ocupación en la ganadería, que aparece con expresiones como "pastor", "ganadero", "mayoral de cabaña" o "esquilador".

\begin{tabular}{|c|c|c|c|c|}
\hline Ocupación del esposo & De casada & De viuda & Total & $\%$ \\
\hline Sector Primario & 89 & 89 & 178 & \\
\hline Campo $^{*}$ & 83 & 83 & 166 & 93.25 \\
\hline Cañero & & 1 & 1 & 0.56 \\
\hline Pastor & 3 & 3 & 6 & 3,37 \\
\hline Ganadero & 1 & & 1 & 0,56 \\
\hline Mayoral de cabaña & & 1 & 1 & 0,56 \\
\hline Esquilador & 2 & 1 & 3 & 1,68 \\
\hline Sector Secundario & 70 & 74 & 144 & \\
\hline De la seda & 12 & 8 & 20 & 13,88 \\
\hline Torcedor de seda & 3 & & 3 & 2,08 \\
\hline Tejedor & 1 & 1 & 2 & 1,38 \\
\hline Mediero & & 1 & 1 & 0,69 \\
\hline De la lana & 5 & 2 & 7 & 4,86 \\
\hline Tejedor de paño & & 1 & 1 & 0,69 \\
\hline Tintorero & 1 & & 1 & 0,69 \\
\hline Tundidor & & 1 & 1 & 0,69 \\
\hline Tejedor de lienzo & 2 & 5 & 7 & 4,86 \\
\hline Lencero & & 1 & 1 & 0,69 \\
\hline Sastre & & 3 & 3 & 2,08 \\
\hline Cordonero & 1 & 1 & 2 & 1,38 \\
\hline Monterero & 1 & & 1 & 0,69 \\
\hline Curtidor & 1 & & 1 & 0,69 \\
\hline Corambrero & & 1 & 1 & 0,69 \\
\hline Talabartero & 1 & & 1 & 0,69 \\
\hline Del cáñamo & 1 & 1 & 2 & 1,38 \\
\hline Linero & 1 & 1 & 2 & 1,38 \\
\hline Zapatero & 10 & 13 & 23 & 15,97 \\
\hline Alpargatero & 5 & 5 & 10 & 6,94 \\
\hline Restillador & 1 & 1 & 2 & 1,38 \\
\hline Taconero & 1 & & 1 & 0,69 \\
\hline Albañil & 5 & 7 & 12 & 8,33 \\
\hline Carpintero & 2 & 5 & 7 & 4,86 \\
\hline Sillero & & 2 & 2 & 1,38 \\
\hline
\end{tabular}




\begin{tabular}{|c|c|c|c|c|}
\hline Herrero & 4 & 2 & 6 & 4,16 \\
\hline Calderero & 1 & & 1 & 0,69 \\
\hline Almirecero & & 2 & 2 & 1,38 \\
\hline Cerrajero & 2 & & 2 & 1,28 \\
\hline Alfarero & 1 & 1 & 2 & 1,38 \\
\hline Tornero & 2 & & 2 & 1,38 \\
\hline Pintor & 1 & 2 & 3 & 2,08 \\
\hline Fontanero & & 2 & 2 & 1,38 \\
\hline Cerero & 1 & 1 & 2 & 1,38 \\
\hline Tallista & & 1 & 1 & 0,69 \\
\hline Cantero & 1 & & 1 & 0,69 \\
\hline Papelero & 1 & & 1 & 0,69 \\
\hline De la pólvora & 1 & & 1 & 0,69 \\
\hline Molinero & 1 & 3 & 4 & 2,77 \\
\hline Sector Terciario & 35 & 45 & 80 & \\
\hline Sirviente & 8 & 6 & 14 & 17,5 \\
\hline Arriero & 1 & 6 & 7 & 8,75 \\
\hline Cosario & & 1 & 1 & 1,25 \\
\hline Cochero & 1 & & 1 & 1,25 \\
\hline Músico & 1 & 3 & 4 & 5,00 \\
\hline Barbero & & 3 & 3 & 3,75 \\
\hline Peluquero & 2 & & 2 & 2,50 \\
\hline Panadero & 3 & 4 & 7 & 8,75 \\
\hline Verdulero & 1 & & 1 & 1,25 \\
\hline Quincallero & 1 & 1 & 2 & 2,50 \\
\hline Mercader & & 1 & 1 & 1,25 \\
\hline Dependiente de rentas & 1 & 5 & 6 & 7,50 \\
\hline Corredor & & 1 & 1 & 1,25 \\
\hline Médico & 1 & & 1 & 1,25 \\
\hline Escribano (inc. oficial de pluma) & 1 & 3 & 4 & 5,00 \\
\hline Receptor & & 1 & 1 & 1,25 \\
\hline Menistro & & 1 & 1 & 1,25 \\
\hline Procurador & & 1 & 1 & 1,25 \\
\hline Factor del Voto & & 1 & 1 & 1,25 \\
\hline Maestro de escuela & & 2 & 2 & 2,50 \\
\hline Militar (inc. capitán) & 6 & 2 & 8 & 10,00 \\
\hline Soldado/marinero & 5 & 3 & 8 & 10,00 \\
\hline Inválido & 2 & & 2 & 2,50 \\
\hline Mendigo & 1 & & 1 & 1,25 \\
\hline Se desconoce & 11 & 10 & 21 & \\
\hline Total & 205 & 218 & 423 & \\
\hline
\end{tabular}

* Habitualmente consigna la expresión "del campo", con frecuencia "jornalero" y raramente "hortelano" o "labrador".

Tabla 11. Ocupación de los esposos de las hospitalizadas en 1804.

Fuente: AHCRG, Libros de ingresos de enfermas. 
El sector secundario está representado por profesiones relativas a la actividad industrial. Las enfermas cuyo marido se dedica al variopinto mundo de la artesanía están presentes en un número muy importante, y representan algo más de la tercera parte de las profesiones consignadas, como corresponde a una ciudad con importante significación en este campo. Las actividades propias de la industria textil son, como no podía ser de otra manera, las más relevantes, tanto con profesiones relativas a la fabricación de tejidos de seda -que aparecen con expresiones como "de la seda" o "torcedor de seda"- actividad que tras una profunda crisis experimentó una relativa recuperación en la segunda mitad del siglo XVIII, como otras relativas a la fabricación de paños y lienzos - "tejedor de paños", "tejedor de lienzos", "tejedor" sin más, "tundidor", "lencero", "tintorero", "linero"-. También está presente la importante industria del cuero, con oficios como los de "curtidor", "corambrero", "talabartero". Y el abigarrado y multicolor mundo de los gremios, en muy variadas actividades: "mediero", "sastre", "cordonero", "monterero", "zapatero", "alpargatero", "calderero", "almirecero", "cerrajero", "alfarero", "tornero", "herrero", "sillero"... No faltan tampoco las enfermas con maridos relacionados con el mundo de la construcción, que junto con el textil era el más importante en el Antiguo Régimen, con profesiones como: "albañil", "carpintero", "pintor", "fontanero", "cantero", etc.

En cuanto al sector terciario, tiene un porcentaje más bajo, aunque relativamente importante, se acerca al 20 por ciento del total, como corresponde a una ciudad de servicios por ser un importante núcleo administrativo, con un elenco de instituciones muy importantes tanto del Estado como de la Iglesia. Hay que señalar la escasa presencia del mundo del comercio, al menos como actividad especializada, entre las hospitalizadas solo encontramos las viudas de un mercader y de un corredor. Es lógico, pues en esta última actividad el poder económico no haría necesario acogerse en un hospital de pobres como este. La mayoría de las mujeres de este sector podrían ubicarse en el amplio mundo de los servicios, sus maridos estaban entre los dependientes y subalternos de las instituciones granadinas, no procedían del mundo de los funcionarios propiamente dichos, sectores acomodados que a priori tampoco serían "clientes" de un hospital benéfico como el que nos ocupa. Destaca un número importante de esposas o viudas de sirvientes, junto a otras que los son de cocheros, barberos, peluqueros, militares, y alguna con marido dependiente de rentas, escribano, receptor, procurador, factor del voto, maestro de escuela, etc. La posibilidad de los dependientes de estos oficios subalternos de caer en la pobreza era algo real en el Antiguo Régimen y más llegando el caso de la viudedad. Hay que señalar también la única presencia de la esposa de un mendigo, lo que demuestra que el mundo de la marginalidad no tuvo mucha cabida en este hospital que, a nuestro juicio, se destinó más a una pobreza digna y en cierto modo honorable.

\section{LAASISTENCIA SANITARIA}

Por lo general los libros de ingresos de las enfermas en el hospital no proporcionan información acerca de las enfermedades que causan las hospitalizaciones, no obstante, en alguna ocasión sí se registra esta valiosa información, como ocurre en 1804 . 
En este año, de los 680 ingresos que se produjeron en el hospital, se consigna la enfermedad que padecen 647 mujeres. Casando estos datos con los procedentes del libro de defunciones podemos saber qué enfermedades tuvieron mayor presencia en el hospital durante ese año y de estas cuáles tuvieron una mayor mortalidad.

\begin{tabular}{|l|c|c|c|c|}
\hline \multicolumn{1}{|c|}{ Enfermedades } & $\mathbf{N}^{\mathbf{0}}$ de ingresos & \% ingresos & Fallecimientos & \% Fallecimientos \\
\hline Tabardillo & 160 & 24,72 & 25 & 15,62 \\
\hline Calenturas & 96 & 14,83 & 9 & 9,37 \\
\hline Tercianas & 78 & 12,05 & 5 & 6,41 \\
\hline Dolores diversos & 50 & 7,72 & 5 & 10,00 \\
\hline Del vientre y estómago & 47 & 7,26 & 1 & 2,12 \\
\hline Plenitud & 25 & 3,86 & & \\
\hline Ciciones & 24 & 3,70 & 2 & 8,33 \\
\hline Erisipela & 22 & 3,40 & & \\
\hline Afecciones nefríticas & 22 & 3,40 & & \\
\hline Debilidad & 21 & 3,24 & 5 & 23,80 \\
\hline Afecciones del pecho & 12 & 1,85 & 1 & 8,33 \\
\hline Caídas & 10 & 1,54 & & 85,71 \\
\hline Hidropesía & 7 & 1,08 & 6 & 13,32 \\
\hline Otras menos relevantes & 73 & 11,28 & 9 & \\
\hline Total & 647 & & 68 & \\
\hline
\end{tabular}

Tabla 12. Prevalencia de enfermedades en el Hospital de la Caridad y Refugio de Granada en 1804.

Fuente: AHCRG, Libros de ingresos de enfermas y Libros de fallecidas.

Como puede observarse, según los datos de que disponemos, al menos en 1804 la mayoría de las enfermas ingresadas en el Hospital del Refugio de Granada lo hicieron por enfermedades de tipo infeccioso, como el tabardillo, denominación que se empleaba popularmente para referirse al tifus, enfermedad que más asistencias requirió (casi una cuarta parte de los ingresos se debieron a esta enfermedad), la erisipela, o variados tipos de fiebres -calenturas sin especificar, o de diversos tipos (calenturas malignas, recesivas, mesentéricas, tercianas, etc.)-, que sumadas todas ellas arrojan un porcentaje que alcanza el 55 por ciento del total de las enfermas. Menor significación, aunque el número de ingresos sea importante, presentan las hospitalizadas a causa de procesos dolorosos de diversa índole, que alcanzan el medio centenar; parecida cifra tuvieron las afecciones que podemos considerar digestivas, de vientre y estómago, y algo menos las aquejadas por ciciones y plenitud ${ }^{63}$. También hay un número relativamente importante de ingresadas por afecciones nefríticas y por debilidad, en algunos de los casos se califica de debilidad esencial, pensamos que

63 Para identificar las enfermedades a partir de las denominaciones de la época: Diccionario de ciencias médicas por una sociedad de los más célebres profesores de Europa, traducido al castellano por varios facultativos de esta Corte, Madrid, Imprenta de D. Mateo Repullés, 1821-1826, 39 vols. En cuanto a ciciones se trata de "calenturas intermitentes que entran con frío", significando plenitud una "abundancia o exceso de un humor en el cuerpo" (Diccionario de la Real Academia Española de la Lengua). 
quizá esta denominación podría responder a estados que hoy calificamos de anemia o malnutrición. No faltan otras enfermedades, como afecciones del pecho, accidentes como caídas, o denominaciones que parecen precisas, como la hidropesía, acumulación de líquidos en los tejidos, que no informan, sin embargo, sobre el origen de este síntoma. El resto de las hospitalizadas lo fueron por diversas enfermedades mucho más variadas.

Entre las enfermedades consignadas, las más letales, fueron la hidropesía, con una mortalidad que superó al 85 por ciento de los ingresos, seguida a mucha distancia por la debilidad, casi una cuarta parte de las ingresadas por esta causa murieron, y el tabardillo, enfermedad por la cual murió más del 15 por ciento de las afectadas. El resto de las enfermedades produjo muertes del 10 por ciento de las pacientes, y más bajas.

\begin{tabular}{|l|c|c|c|c|}
\hline \multicolumn{1}{|c|}{ Enfermedad consignada } & $\mathbf{N}^{\mathbf{0}}$ casos & $\begin{array}{c}\text { \% sobre el total } \\
\text { de fallecidas }\end{array}$ & $\begin{array}{c}\text { Edad } \\
\text { media }\end{array}$ & $\begin{array}{c}\text { Estancia } \\
\text { media días }\end{array}$ \\
\hline Tabardillo & 25 & 36,76 & 43,3 & 11 \\
\hline $\begin{array}{l}\text { Calenturas (incluida calentura maligna, } \\
\text { recesiva, inflamatoria y mesentérica) }\end{array}$ & 9 & 13,23 & 51,77 & 9,3 \\
\hline Hidropesía & 6 & 8,82 & 51,72 & 22,16 \\
\hline Dolor (incluido de costado y convulsivo) & 5 & 7,35 & 46,4 & 10,2 \\
\hline $\begin{array}{l}\text { Debilidad (en algunos casos debilidad } \\
\text { esencial) }\end{array}$ & 5 & 7,35 & 60,2 & 9,4 \\
\hline Tercianas & 5 & 7,35 & 40,8 & 19,2 \\
\hline Ciciones & 2 & 2,94 & 43,5 & 8 \\
\hline Afección de estómago & 1 & 1,47 & 31 & 32 \\
\hline Indigestión & 1 & 1,47 & 48 & 13 \\
\hline Cuartanas & 1 & 1,47 & 66 & 17 \\
\hline Alferecía & 1 & 1,47 & 4 & 0 \\
\hline Flujo de sangre & 1 & 1,47 & 18 & 8 \\
\hline Edema & 1 & 1,47 & 40 & 19 \\
\hline Afección de pecho & 1 & 1,47 & 47 & 29 \\
\hline Reumatismo & 1 & 1,47 & 64 & 5 \\
\hline No consta & 3 & 4,41 & 55,83 & 34 \\
\hline Total y medias & 68 & 99,97 & 46,4 & 13,7 \\
\hline
\end{tabular}

Tabla 13. Letalidad en el Hospital de la Caridad y Refugio de Granada en 1804. Fuente: AHCRG, Libros de ingresos de enfermas y Libros de fallecidas.

De las 68 mujeres que murieron en 1804 en el hospital, más de la tercera parte lo hicieron a causa del tabardillo, enfermedad que, aunque no era la más letal, registró el mayor número de hospitalizaciones. Le siguen las muertes provocadas por "calenturas" (valores que superan al 13 por ciento del total), por hidropesía, es decir, por acumulación de líquido seroso, enfermedad de gran letalidad por la que hubo pocos ingresos, pero murieron la mayoría (cuyas muertes se acercan al 10 por ciento de las 
producidas en el hospital), y por dolores, debilidad y tercianas ${ }^{64}$, con cinco muertes cada una. El resto de las muertes se producen por enfermedades muy variadas: ciciones, afecciones del estómago, cuartanas, alferecía (nombre con el que se denominaba entonces a las convulsiones y a la epilepsia, incluso a casos de apoplejía), flujo de sangre, edema, reumatismo, etc.

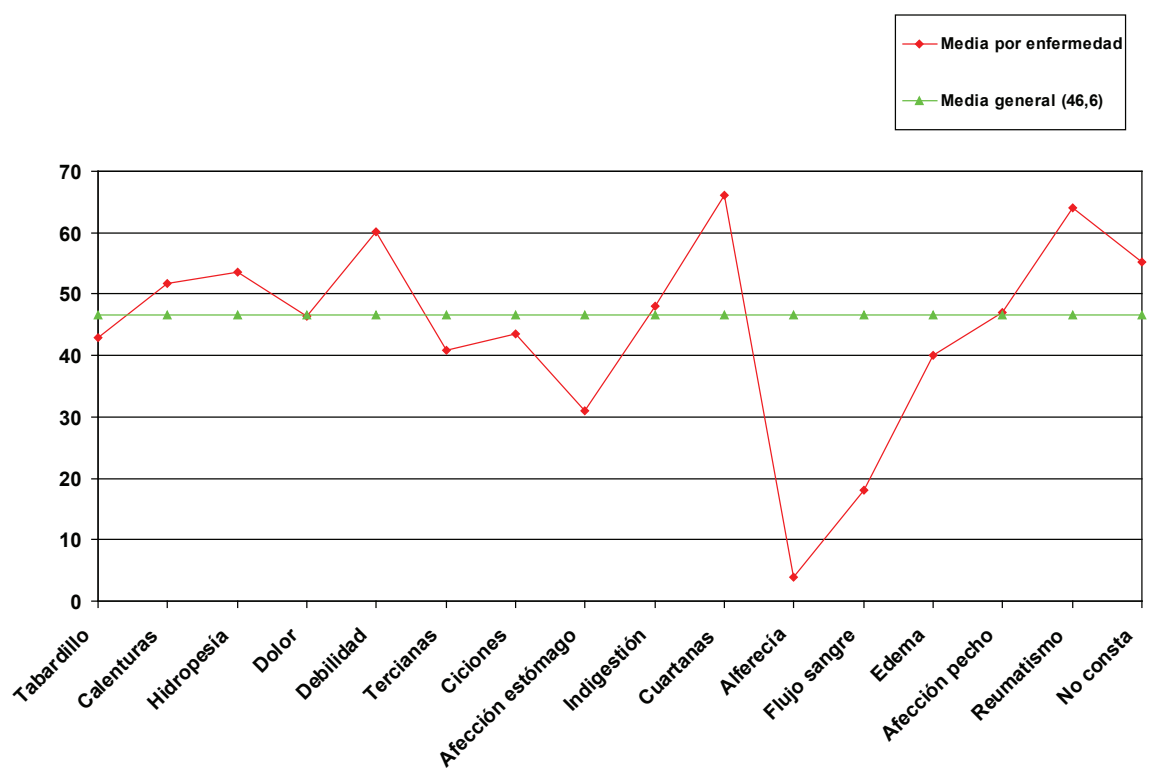

Tabla 14. Edad de las enfermas fallecidas en el Hospital de la Caridad en 1804.

Fuente: AHCRG, Libros de ingresos de enfermas y Libros de fallecidas.

En general, la edad media de las enfermas que mueren es bastante alta, aunque este dato puede matizarse por enfermedades. Dejando al margen el caso de una enferma de cuartanas y otra de reumatismo, por tratarse de un único caso, la edad más alta la presentan las aquejadas de debilidad, con una edad media superior a 60 años, seguidas de las enfermas de calenturas (casi 52 años de media) e hidropesía (superan los 51 años de media). En general, las enfermas que murieron superaban los 40 años, si se exceptúa a una mujer de 31 años que murió de una afección de estómago, una joven de 18 años, que falleció a consecuencia de un flujo de sangre y una niña de 4 años que murió a causa de un ataque de alferecía.

64 Las fiebres tercianas eran una constante endémica en algunas regiones mediterráneas españolas, como Valencia y Murcia, y presentaron brotes epidémicos en algunos momentos, como 1783 (PESET: op. cit. (nota 56), pp. 39 y ss). 


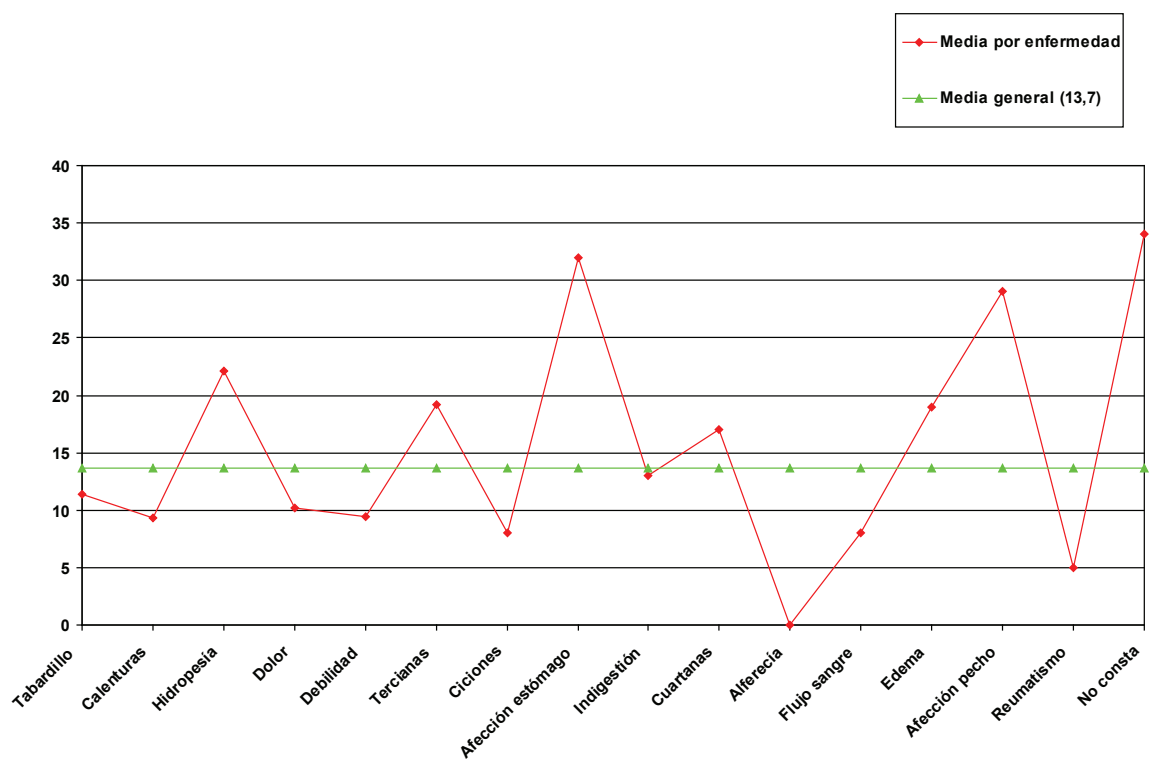

Tabla 15. Estancia de las enfermas fallecidas en el Hospital de la Caridad en 1804. Fuente: AHCRG, Libros de ingresos de enfermas y Libros de fallecidas.

La estancia media de estas fallecidas en el hospital se acerca a los 14 días, pero es muy variada, junto a una enferma del estómago, que murió cuando llevaba más de un mes en el hospital, la referida niña muerta a causa de la epilepsia solo estuvo unas horas en el centro benéfico. Por enfermedades, es la hidropesía la que registra las estancias más largas, que superan los 22 días de hospitalización.

$$
* * *
$$

Como podemos observar por la muestra estudiada, el hospital de la Caridad y Refugio era una de las instituciones sanitarias más importantes de la Granada del Antiguo Régimen. Durante la segunda mitad del siglo XVIII desplegaba una importante actividad y contribuía a paliar el dolor y la enfermedad del colectivo femenino aquejado por la pobreza. Pero no por una pobreza marginal propia del mundo de la exclusión social, sino por la pobreza estructural que aquejaba a amplios sectores de los del campesinado y del artesanado, propia de una sociedad profundamente desigual como era la española en el Antiguo Régimen.

En este sentido cumplió perfectamente su función social de tutela de la mujer, y de atención a sus necesidades, en sectores modestos de la población, eso sí considerados honestos, en la línea de la propia honorabilidad y ejemplaridad que distinguía a la ilustre corporación que fundó y regía el centro hospitalario, sin duda con un gran esfuerzo económico.

Evidentemente en la práctica diaria de la atención sanitaria confluían móviles sociales y religiosos, como cabía esperar de una sociedad sacralizada. No es en puridad 
un hospital eclesiástico, sino dependiente de una hermandad, pero como todos los centros hospitalarios de la época, la presencia clerical era necesaria y la ideología sustentante se hallaba plenamente transida de la doctrina cristiana. De hecho, la Hermandad de la Caridad y Refugio se afanaba en dar pleno cumplimiento a todas las obras de misericordia corporales.

Siempre tuvo este hospital para mujeres un reconocido prestigio en la sociedad granadina. Y ello puede deberse en partes iguales a la distinción de los miembros de la Hermandad y al cuidado puesto en la atención sanitaria. Lo más revelador de todo, a la luz de las estadísticas de ingresos y fallecimientos manejadas para finales del siglo XVIII y comienzos del XIX, es que el índice de curación era realmente elevado, considerando que ni admitía enfermas "incurables", lo que imprimía fundadas esperanzas a las mujeres que se veían obligadas a acudir a él -mayoritariamente mujeres solas, es decir solteras y viudas-. Sin duda se trataba de un centro de referencia, por todos los motivos expuestos, enclavado en el mismo corazón de la ciudad. 